\title{
Intracranial self-stimulation in the pigeon: The effects of current intensity
}

D. M. WEBSTER and I. L. BEALE, University of Auckland, Auckland, New Zealand

A key-pecking response in pigeons was shaped and maintained by intracranial stimulation as the sole reinforcer, using current levels of stimulation up to 500 microA. Orderly functions relating response rate to stimulation intensity were obtained. High local rates of pecking were obtained at all intensities of stimulation, but rests from pecking were longer at lower intensities.

The self-stimulation phenomenon has been reported in fish by Boyd \& Gardner (1962) and in many mammals from rodents (Olds \& Milner, 1954) to man (Heath \& Mickle, 1960). It has also been described in birds by Macphail (1966, 1967) who, however, reported difficulty in "establishing a satisfactory operant level of any response that can be used to operate a microswitch." Intracranial stimulation has been used in studies not primarily concerned with the self-stimulation phenomenon as a practical and convenient means of reward, e.g., Trowill (1967) and Miller \& DiCara (1967). The ubiquity of pigeons in operant research suggests that preparations in which a key-peck response can be established and maintained, using only electrical brain stimulation as reward, may have wide application, especially where traditional rewards might interfere with stimulus control or a relevant dependent variable such as interresponse time. The feasibility of such a technique was the subject of this study. METHOD

The experiment used a standard operant-conditioning chamber containing a single transparent key of .75-in. diam that required a force of $20 \mathrm{~g}$ to operate. A screen behind the key was illuminated with white light.

Eight experimentally naive homing pigeons were implanted bilaterally with monopolar electrodes aimed at the neostriatum. These were stainless steel needles, insulated with acrylic enamel, air dried, bared $0.5 \mathrm{~mm}$ at the tip, and baked. Stereotaxic coordinates were taken from a stereotaxic atlas for the brain of the White Carneau pigeon prepared by Karten \& Hodos (1967). The Revzin pigeon adaptor described in this atlas was found suitable for locating the homing pigeons used by us in a standard stereotaxic instrument for the cat. The neostriatum was chosen primarily because Macphail's work suggested that stimulation of that area might be positively reinforcing, while stimulation of areas rewarding in mammals (e.g., septum and medial forebrain bundle) was apparently aversive. A Halothane and nitrous oxide mixture was used to anesthetize the pigeons while electrodes were implanted and fixed to the skull with dental cement. The cement also held an indifferent terminal connected to a wire loop fixed to the skull.

On recovery each bird was placed in the experimental chamber for at least $1 \mathrm{~h}$ while an attempt was made to shape a key peck using brain stimulation as the only reinforcer. Stimulation was a $.5-\mathrm{sec}$ train of 50 cycle sine wave of adjustable current intensity. For each bird, gratuitous stimulation was given to determine an effective current level. A series of bipolar stimulations were given, the current intensity increasing from 50 microA in steps of 50 microA, to a maximum of 500 microA or until an obvious startle response was elicited. This minimum effective current was used during the key-peck shaping. Birds failing to key peck for bipolar stimulation were then tried on stimulation between the indifferent and each side in turn. However, none of the birds that failed to key peck for bipolar stimulation improved subsequently when the stimulation was given to either side. Three of the four birds that failed to key peck appeared to find the brain stimulation aversive on at least one side. Four of the eight birds learned within the hour to peck the key to deliver their own brain stimulation. The other four were eventually discarded.

Following the initial shaping session, the four self-stimulators were given several daily sessions on self-stimulation at the current level used for shaping. This established that brain stimulation for every peck would maintain rates of pecking in excess of 3,000 per $h$ for $4 \mathrm{~h}$ or more in a continuous session. Then the birds were given five daily $1-h$ sessions in which five current levels $(100,200,300,400$, or 500 microA) were tried, according to a varied series different for each bird. For these sessions stimulation was bipolar. Two further such series of five sessions were then given in which stimulation was between the indifferent and the right and left electrodes in turn. Stimulation was given for every peck.
Following testing all birds were sacrificed and perfused with formol saline. Brains were fixed in formalin for 3 weeks, and were then blocked in the plane of electrode insertion and sectioned in the same plane on a freezing microtome. Sections through each electrode tract were stained for Nissl substance with cresyl echt violet and examined for evidence of lesion. In most cases, there was damage around the electrode tip. The placements of the three self-stimulators used in the study of current intensity are shown in Fig. 1. These were mainly in the neostriatum but two were in the region of the lamina medullaris dorsalis. The placements in four birds that failed to self-stimulate were in this area in one case only (lamina medullaris dorsalis). In two cases the placements were too anterior, missing the brain or passing through it. In the other case, they were in the ectostriatum.

\section{RESULTS AND DISCUSSION}

Response rates at each current level are given for three birds in Fig. 2. Complete results were not available for the fourth bird, which was sacrificed after its electrode crown became dislodged. For S52 and S56, response rate increased with current intensity up to 400 microA, then decreased at 500 microA. This was true of all modes of stimulation, except that for S52 the function for the left side peaked at

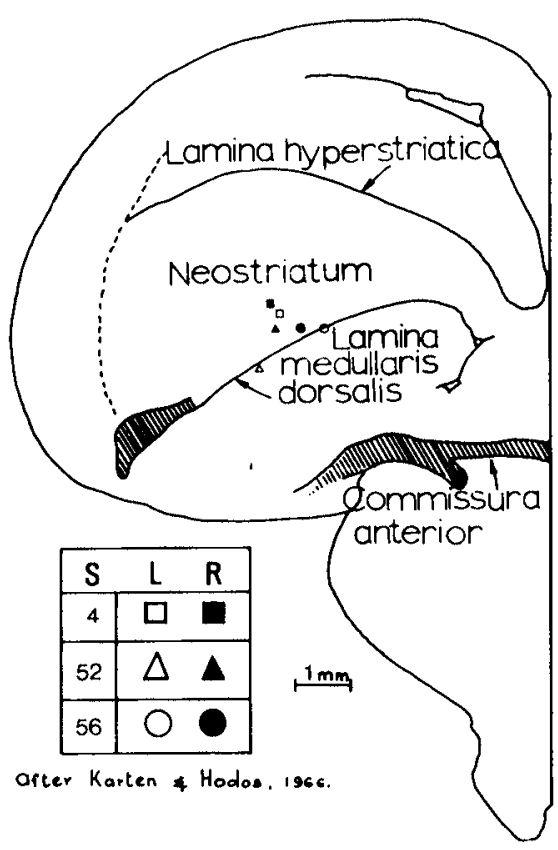

Fig. 1. Section in the plane of implantation, showing placement of electrode tips in three self-stimulating pigeons. Left and right placements are indicated by open and solid symbols, respectively. 

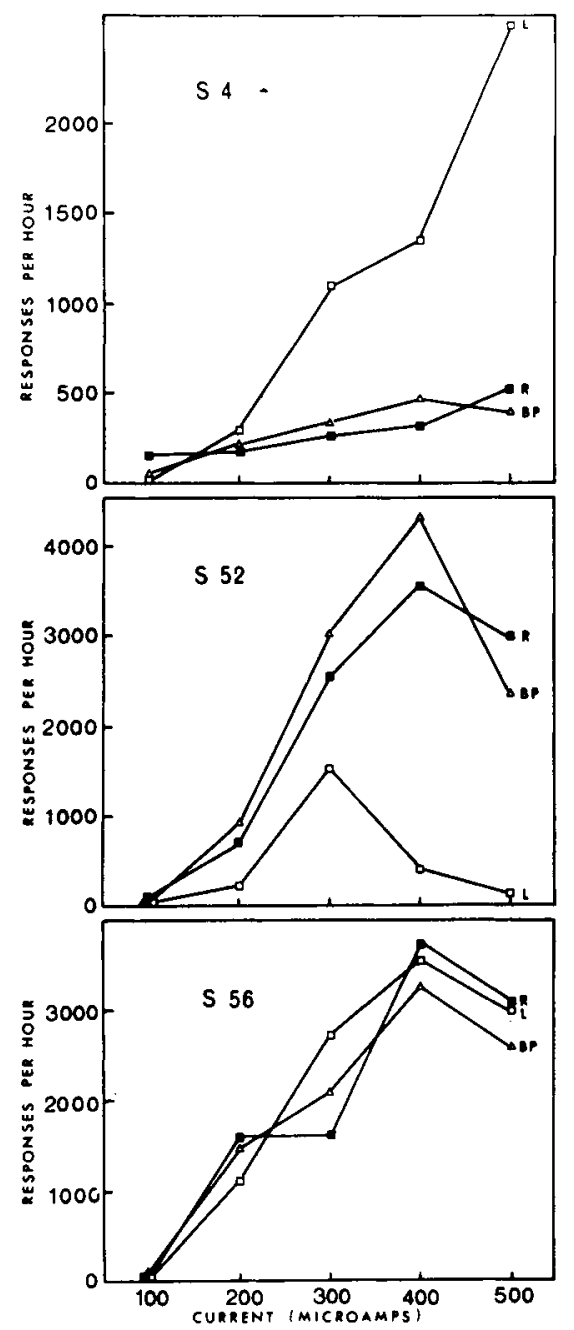

Fig. 2. The graphs show responses per hour at five current levels for three modes of stimulation: left, right, and bipolar (see text). Individual birds are shown separately.

300 microA. Two of the three functions for S4 showed response rates increasing with current intensity right up to 500 microA. As Hawkins \& Pliskoff (1964) have shown, curves relating response rate on continuous reinforcement to intensity of stimulation should not be interpreted as curves of magnitude of reinforcing effects. The curves simply provide an indication of

Fig. 3. Cumulative records of responding for CRF stimulation at five current levels. These records are of $\mathbf{S 5 2}$ with stimulation on the right electrode. Slope of graph corresponds to rate of responding. Every tenth response is marked by an oblique excursion of the pen. These records are typical of those produced by all three self-stimulators under all modes of stimulation. the response rate controlled by stimulation at several current levels.

Comparison of Figs. 1 and 2 shows that the differences between the functions for right and left electrodes in S4 and S52 are not apparently related to placement of the electrode tips in relation to gross brain anatomy. It is more likely the result of finer anatomical distinctions in the stimulated areas or of differential effects of implantation per se.

The current intensity threshold for self-stimulation in these pigeons is high, when compared with mammalian species

\section{$1 \mathrm{CO}_{\mathrm{Ha}}$}
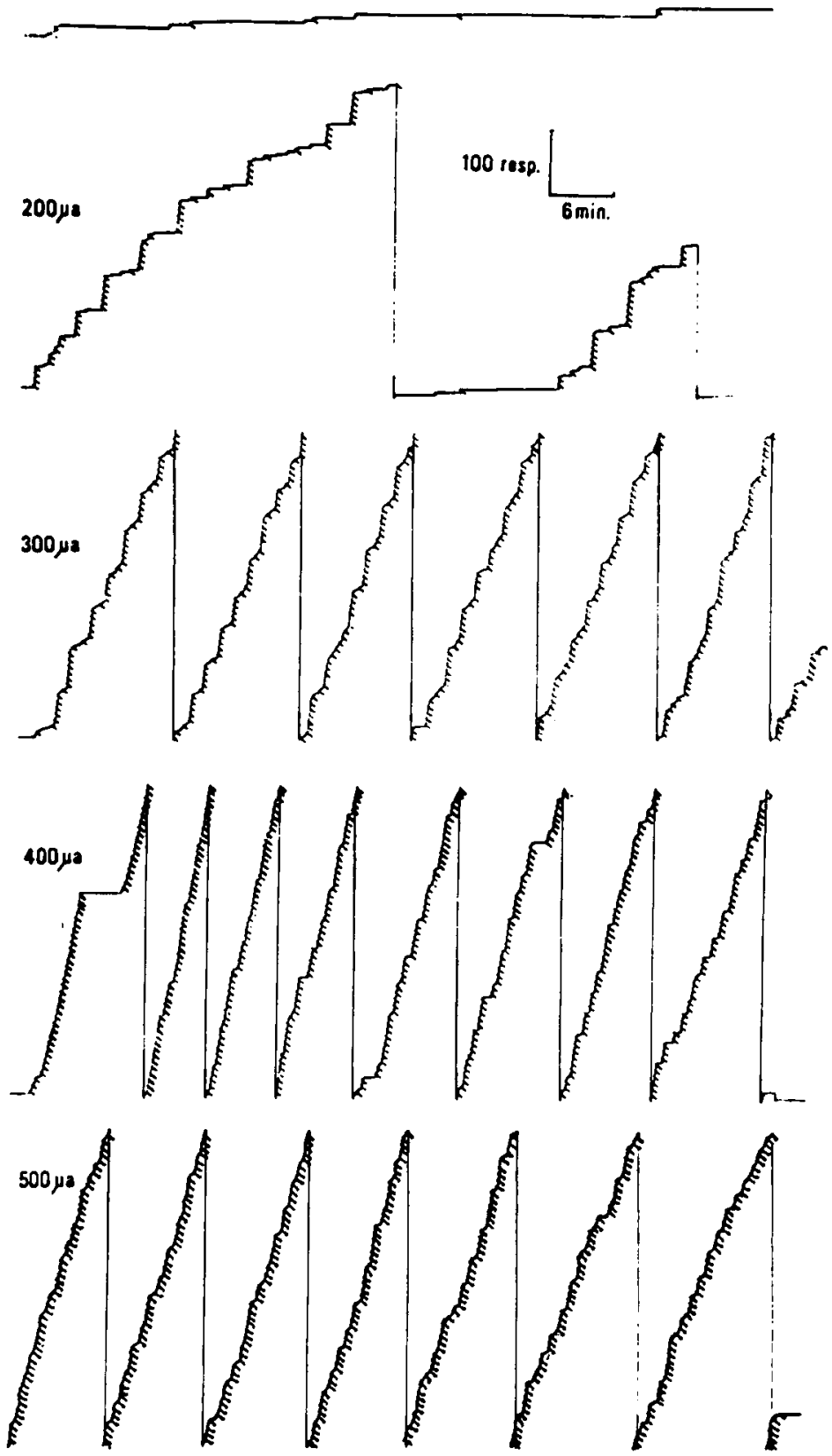
high current levels is clearly conditional upon the extent of damage to the brain caused by the stimulation. Histology showed that gliosis at the electrode tips was comparable to that found in rats following a similar history of stimulation at low current intensities. Lesion attributable to stimulation appeared to be restricted to a small area around the electrode tip.

The pattern of responding at the various current levels may be seen in the cumulative records presented in Fig. 3 . The cumulative records show bursts of high rate of responding at all current levels. These bursts are separated by periods of responding at a very low rate. The periods of low rate are long and frequent at low current levels and decrease in length and frequency as current level increases. This was characteristic of the cumulative records of all three birds. During bursts of high rate, stimulation was often continuous for long periods, since every peck produced a $0.5-\mathrm{sec}$ stimulation. This suggested the possibility that responding was maintained primarily by continuous stimulation and that responding might not be maintained in a situation where prolonged stimulation was not possible. This was investigated in a subsequent study where it was found that very high, uniform rates of responding developed on a fixed-ratio schedule where stimulation followed every tenth response. On this schedule, continuous stimulation was possible only if rates exceeded 20 per sec. Such a condition was in fact not attained, indicating that prolonged stimulation was not an essential factor.

\section{REFERENCES}

BOYD, E. S., \& GARDNER, L. C. Positive and negative reinforcement from intracranial stimulation of a teleost. Science, 1962, 136, 648-649.

HAWKINS, T. D., \& PLISKOFF, S. S. Brain stimulation intensity, rate of self-stimulation, and reinforcement strength: An analysis through chaining. Journal of the Experimental Analysis of Behavior, 1964, 7, 285-288.

HEATH, R. G., \& MICKLE, W. A. Evaluation of seven years experience with depth electrode studies in human patients. In E. R. Ramsey and D. S. O'Doherty (Eds.), Electrical studies on the unanaesthetized brain. New York: Paul B. Moeber, 1960.

KARTEN, H. J., \& HODOS, W. A stereotaxic atlas of the brain of the pigeon. Baltimore: Johns Hopkins Press, 1967.

MACPHAIL, E. M. Self-stimulation in pigeons: The problem of "priming." Psychonomic Science, 1966, 5, 7-8.

MACPHAIL, E. M. Positive and negative reinforcement from intracranial stimulation in pigeons. Nature, 1967, 213, 947-948.

MILLER, N. E., \& DiCARA, L. Instrumental learning of heart-rate changes in curarized rats: Shaping and specificity to discriminative stimulus. Journal of Comparative \& Physiological Psychology, 1967, 63, 12-19.

OLDS, J., \& MILNER, P. Positive reinforcement produced by electrical stimulation of the septal area and other regions of rat brain. Joumal of Comparative \& Physiological Psychology, 1954, 47, 419-427.

OLDS, J. Self-stimulation of the brain. Science, 1958, 127, 315-324.

TROWILL, J. A. Instrumental conditioning of the heart rate in the curarized rat. Journal of Comparative \& Physiological Psychology, $1967,63,7-11$.

\title{
A test of the "ceiling effect" hypothesis of positive contrast*
}

\author{
PATRICK E. CAMPBELL, CHARLES M. CRUMBAUGH, \\ STEPHEN B. KNOUSE, and M. EMILY SNODGRASS $\dagger$ \\ Southern Methodist University, Dallas, Tex. 75222
}

Seventy-two rats were given $0,5,10$, or 15 small rewarded trials prior to being shifted to large reward for the remainder of 45 trials. Each of the groups which experienced an upward shift in reward magnitude rapidly approximated the performance of a consistently large rewarded control group, and in no case was a positive contrast effect observed. The performance curves for all the groups remained interlaced for a rather protracted period of asymptotic training. The results were discussed in terms of their relevance to the "ceiling effect" hypothesis of the absence of positive contrast.

*This research was partially supported by Grant No. GU.3093 from the National Science Foundation to Southem Methodist University. The study was conducted according to the APA statement of "Principles for the care and use of animals," June 26, 1968. We would like to acknowledge the assistance of Ken Husa and Steve Prestwood for matters relating to computer analysis of the data. Reprints may be obtained from Patrick E. Campbell, Department of Psychology, Southern Methodist University, Dallas, Tex. 75222.

+Now at the State University of New York at Stony Brook.
The effect of a given amount of reward sometimes depends upon the "context" in which the reward occurs. For example, both Crespi (1944) and Zeaman (1949) reported that rats trained at a small reward and then shifted to a large reward tended to "overshoot" the performance level estimated for animals exposed only to the larger reward. Although this phenomenon was originally termed an "elation effect," the term "positive-contrast effect" (PCE) is more generally used today. In addition to the PCE, Crespi and Zeaman also reported the reciprocal effect, i.e., rats trained at a large reward and subsequently shifted to a small reward tended to show a "depression" or a negative-contrast effect (NCE) by "undershooting" the estimated performance of a consistently small rewarded group.

In more recent years both the PCE and the NCE have proved to be reasonably reliable phenomena in the free-operant situation (Reynolds, 1961). Nevertheless, two recent reviews of the literature, dealing mainly with the simple discrete-trial instrumental or selective learning situations, have suggested that the NCE frequently occurs in such situations but the symmetrical finding of a PCE seldom occurs (Black,1968; Dunham, 1968). One possible explanation of the failure to find the PCE is the "ceiling hypothesis" suggested by Bower (1961). According to that view, the PCE might be prevented when the performance of a large-reward control group is at or near some pysical limit. The absence of the PCE might be seen, then, not as a matter of behavioral principles, but as an artifact of experimental design.

The purpose of the present experiment was to test this hypothesis by varying the number of small rewarded trials $(0,5,10$, 15) prior to a shift to large reward. Two other experiments have reported similar designs but, unfortunately, their experiments were conducted for other reasons, and the shifts from small to large reward occurred well after the consistently large rewarded group had reached asymptote (Ashida \& Birch, 1964; Birch \& Valle, 1967).

\section{SUBJECTS}

The Ss were 72 experimentally naive male albino rats of the Sprague-Dawley strain, selected from the colony at Southern Methodist University. Ss were approximately 80 days old at the outset of training.

\section{APPARATUS}

The apparatus, a black plastic Hunter small-animal runway, was 74 in. long, $3.25 \mathrm{in}$. wide, and 5 in. high. The entire length was covered with a removable plastic top and the floor consisted of .13 -in. grids spaced .5 in. apart. The final 12-in. section served as a goalbox and was separated from the remainder of the runway by a guillotine door. A stainless steel food cup was mounted approximately 1.5 in. above the grid floor and at the extreme distal end of the goalbox. Response times were measured over three sections of the runway by a system of photoelectric relays wired to control Standard Electric clocks (.01-sec units). 